\title{
"An Overwhelming Cloud of Inertia": Evaluating the Impact of Course Design Changes Following the COVID-19 Pandemic
}

\author{
Joann S. Olson \\ Rita Kenahan \\ University of Houston-Victoria, USA
}

\begin{abstract}
In the wake of the COVID-19 pandemic, beginning in March 2020, educators at all levels faced the challenge of responding to student needs and utilizing technology for instruction. While much of the emerging research highlights the experiences of students and instructors as they shifted from face-to-face to remote learning, this study explored the experiences of students in a fully online graduate program as the scope of the pandemic was growing. What is the best way to maintain a community of inquiry when so much is changing? This case study explored the impact of a variety of course design changes that sought to help students meet learning objectives while also seeking to alleviate the unanticipated pressures created by external forces. Ultimately, the findings suggest that increased flexibility with due dates and access to course materials were the most helpful strategy for helping students deal with the disruptive events of the semester. In addition, managing the disruptions and finding a sense of balance were important for both instructors and students.
\end{abstract}

Keywords: COVID-19, online, asynchronous, student success, course design

Olson, J. S., Kenahan, R., (2021). "An overwhelming cloud of inertia": Evaluating the impact of course design changes following the COVID-19 pandemic. Online Learning, 25(4), 344-361.

DOI: $10.24059 /$ olj.v25i4.2444 
In early March 2020, the COVID-19 pandemic necessitated extraordinary responses at all levels of education. These shifts were disruptive and have been widely discussed in news and other outlets (e.g., Blumenstyk, 2020; Johnson et al., 2020; Parnia, 2020). Faculty and students alike made countless adjustments in the hopes of salvaging the semester and meeting learning objectives. Advice such as "How to create a minimum viable semester in the midst of a global pandemic" (Mazak, 2020) and "Please do a bad job of putting your classes online" (Barrett-Fox, 2020) encouraged faculty to be realistic in determining what could be done and what should be expected.

For the most part, the conversation focused on how to navigate the shift from in-person learning to remote/online learning. For instructors wanting to maintain continuity throughout the shift (Baker, 2020), being reminded that the best of online teaching draws from a different set of tools and strategies than face-to-face instruction was important. And yet, this focus neglected the impact of the pandemic on course design and delivery for those already teaching and learning online. Given the growth of online education and the near certainty of future pandemics, natural disasters, or other cataclysmic events, it is important to consider how to best serve online students well in these situations, a consideration that has often been overlooked in campus disaster planning (Holzweiss et al., 2020; Van et al., 2010). This case study explores the experiences of graduate students as they navigated the COVID-19 pandemic while enrolled in a fully online master's degree program.

\section{Literature Review}

In setting the stage for this study, it is important to consider three key areas of existing research: disaster response/crisis planning, time management for online student persistence, and the extent to which assumptions about best practices for online learning are applicable to crisis situations.

\section{Disaster Response and Crisis Planning for Online Learning}

Research is beginning to emerge related to the impact of COVID-19 on higher education. Abdelmatloub (2020) found that students identified uncertainty over end-of-semester exams as their highest stressor. Those students also "urg[ed] their lecturers to use different means of assessment even if they have to work on more different assignments" (p. 105). In addition, 11\% of Abdelmatloub's participants indicated having issues with online connectivity. Furthermore, Dushkevych et al. (2020) surveyed students during March 2020 and emphasized that keeping to a schedule "creates a sense of continuity [that] ... reduces student anxiety and frustration to uncertainty" (p. 76). Morgan (2020) highlighted the importance of clear communication and also suggested that ensuring equity and responding to the emotional toll of the pandemic would be critical to meeting students' needs during the crisis. Perotta and Bohan (2020) explored the experiences of online faculty who were teaching during this event, highlighting the importance of access to professional development as well as concerns about faculty isolation and academic freedom.

Of course, institutions of higher education have previously faced similar disruptive events. In the wake of the H1N1 ("swine flu") pandemic of 2009, colleges and universities began conversations regarding continuity-of-learning plans, which often included identifying technology and training deficiencies (Davis \& Ash, 2009). In some cases, this planning and evaluation led to "leaders think[ing] more strategically about how e-learning could be part of their overall emergency plan" (Robelen, 2009, p. 18). However, while Meyer and Wilson (2011) found that websites of "flagship institutions" of higher education did instruct faculty, staff, and 
students how to address the H1N1 pandemic, two-thirds of those institutions did not provide any guidance on how to include online learning as a strategy for course continuity.

Holzweiss et al. (2020) extended this exploration of crisis planning for online students through the lens of Hurricane Harvey, which occurred at the beginning of the fall semester in 2017. At the institution that was the focus of their case study, courses were converted from traditional 15week semesters to an accelerated 7.5-week semester. Faculty were incentivized to make this switch with a $\$ 1,000$ stipend/instructor. Focusing on the experiences of the online support team, Holzweiss et al. found that work-around strategies and insufficient access to campus resources (e.g., the student information database) created the greatest challenge. This study also highlighted that students needed additional time to manage the details of their changing course format, while they also dealt with the impact of the hurricane on their personal and family lives. These studies highlight the importance of clearly communicating with students and being responsive to the demands of an emerging situation. In the case of COVID-19, educators and administrators worked to meet the needs of students in the moment. The current study focuses specifically on the experiences of students who were already enrolled in fully online (asynchronous) courses and the impact of mid-semester course design changes.

\section{Time Management for Online Learner Persistence}

Although many factors have an impact on whether students complete their intended course of study (e.g., financial aid, as demonstrated by Qayyum et al., 2019), online students often identify time management as a key challenge to academic success and persistence. This occurs with both undergraduate students (Al-Asfour, 2012; Baker et al., 2019; Elvers et al., 2003; Wandler \& Imbriale, 2017) and graduate students (e.g., Jiang et al., 2019). Procrastination in online courses has been shown to have a negative relationship on class performance (Michinov et al., 2011). Because of this tendency and the potential for negative outcomes, Kesner (2013) suggested that posting deadlines for all work would help keep students on track. Likewise, Wandler and Imbriale (2017) encouraged the use of incremental deadlines for larger assignments as a way to foster student momentum.

Fetzner (2013) researched the experiences of unsuccessful online students. Among these participants, $43.2 \%$ of respondents in Fetzner's study indicated they were not aware that they were expected to start their online coursework on a pre-determined date, suggesting a miscommunication regarding time expectations. Participants were also asked to share the advice they would give to potential online students (Fetzner, 2013). Among the top 13 pieces of advice, the top four clearly connect to time management (e.g., stay up with the course activities - don't get behind; use good time management skills; set aside specific times during each week for your online class).

At the same time, students often approach their learning and course assignments pragmatically, choosing to focus on activities that are directly related to graded activities (Murray et al., 2012). Therefore, some instructors have found value in allowing students to redo assignments, to "[allow] room for learning and growth at their own pace" (p. 308). Some have even chosen to drop assignment deadlines altogether (Barrett, 2019). Glenn (2018) suggested that providing clear outlines and timetables helps students stay on track because the workload feels manageable. ACUE (2020) described this as "establish[ing] a rhythm for participation" (p. 1) in the class that helps students successfully complete the course.

\section{Instructional Design Considerations during a Pandemic}

Garrison et al. (2000) suggested that online learning could be conceptualized as a "community of inquiry" (CoI) wherein teachers and students interact with course content and each other in three 
distinct ways: cognitive presence, social presence, and teaching presence. Cognitive presence speaks to participants' efforts and ability to create meaning from the content presented, a component that Garrison et al. referred to as "most basic to success in higher education" (p. 89). Garrison et al. highlighted the role of social presence - the ways in which learners interact with each other and share enough of their personal characteristics to be perceived as "real people" ( $p$. 89) - as primarily supporting the cognitive activities of the course. Teaching presence includes designing instruction and facilitating the educational discourse. Anderson et al. (2001) expanded teaching presence to also include direct instruction.

A number of design elements emerge from the CoI framework, and the effective design and practice of online education has been the subject of much research (c.f., Sun \& Chen, 2016). Jiang et al. (2019) surveyed graduate-level students in a statistics course who identified having access to recorded lectures with PowerPoint slides (i.e., "direct instruction") as the key to their success in the course. Those same students also indicated that course design — the "spiraling nature of the lessons" (p. 306) - helped them to learn course content effectively. In addition, the students highlighted the importance of online question and answer session with the instructor and other peers (i.e., facilitating discourse). Stone and Springer (2019) found that strong teacher presence and well-designed course materials led to greater student engagement and retention in online classes. Chen and Liu (2020) highlighted the importance of multidimensional discussions to creating social presence, which are sparked by well-designed discussion questions and a clear set of expectations and requirements for discussion forum interaction. For the participants in Terras et al.'s (2018) study, connectivity (i.e., social presence) with the instructor and other advisors was highly valued-more so than connections with other students.

However, what happens to these design "standards" and best practices (e.g., Debattista 2017; Marshall, 2015) when conditions are less than ideal? In the case of COVID-19, the crisis management efforts (e.g., "safe at home" orders, the move to remote learning for K-12 students, and other shutdowns) created additional cognitive load for students and faculty alike. Those changes also affected students' normal strategies for time management. Furthermore, social patterns were disrupted, as were normal modes of teaching. Holzweiss et al. (2020) emphasized the importance of crisis management and swift response to meet the needs of students; they also highlighted the impact of the crisis on instructional design and support staff. This study explores the impact of course design changes on students in an online program in the wake of COVID-19 pandemic during spring semester 2020 asking the research question: To what extent to midsemester course design changes promote student persistence in a fully online course?

\section{Methods}

At CoastalU (a pseudonym), the institution's response to COVID-19 began with closing two days before the regularly scheduled spring break and eventually led to the decision to deliver all courses though online formats during the rest of the semester. Data for this case study (Stake, 1995) were collected at the end of the spring semester. Surveys were completed near the end of the semester, but no data were analyzed until after the instructors posted final course grades.

\section{Course Design and Pandemic Response}

The adult and higher education (AHED) master's degree program at CoastalU is fully online. By design, and for the convenience of students, courses are delivered in an asynchronous format with weekly content and discussion posts as well as periodic assignments with specific due dates throughout the semester. Instructors in the program are committed to the CoI framework, and courses are designed to foster student interaction and cognitive presence. Courses are delivered 
with a strong emphasis on teacher presence and interaction. Although course delivery was not altered by pandemic-related shifts on campus, as the impact of the pandemic spread, faculty in the program discussed course design and schedule changes to best meet the needs of students. Most students work full-time and were facing shifting employment conditions; many work in education and were navigating the uncertainty of the pandemic at their own jobs; and many have young families and were responding to the additional load of facilitating the remote learning of their own children.

In one course (taught by the second author of this article), no changes were made because the program faculty members felt that course content (program planning and design) required a sequential, incremental, and scaffolded approach to best accomplish learning objectives. In the other three courses offered by the department (taught by the first author of this article), the instructor enacted a number of course design changes to give students flexibility in meeting course requirements and learning objectives. Those course changes included: opening all course content folders at once (rather than the typical week-by-week schedule); removing all due dates, deadlines, and penalties for submitting assignments after the posted deadline; changing the grading scale in a way that gave students flexibility to skip two or three discussion forums; and giving students the opportunity to propose an alternative to one of the regular assignments. Temporary university policy also allowed students to choose either satisfactory/unsatisfactory grading or traditional letter grading, a process that occurred separate from the instructor's involvement or knowledge.

\section{Data Collection and Analysis}

We were interested in student response and performance in light of these events and the course design changes. After Institutional Review Board approval (the study was determined to be "exempt"), students enrolled in any of the four AHED classes were invited to fill out a survey that explored their responses to course changes. There were 49 students enrolled in one or more of the four AHED classes offered in spring 2020; 29 survey responses were received, for a 59\% response rate.

Those who chose to participate were asked the extent to which COVID-19 and the corresponding responses (e.g., work changes, social shutdowns, etc.) felt disruptive. They also identified the course design changes that they (a) utilized, (b) found most helpful, and (c) found least helpful. Participants enrolled in the unmodified course were asked which course design change would have been most helpful. In addition, participants responded to several open-ended prompts: the impact of COVID-19 on work and home life, the grading option they chose (satisfactory/unsatisfactory or traditional letter grading), and an open-ended "other comments." In addition, students who were enrolled in at least one modified course and the unmodified course were solicited for semi-structured, qualitative interviews. These interviews explored the students' experience with navigating both modified and unmodified courses. Of the 11 students who were potential participants for this phase of the study, three responded and were interviewed; interviews ranged from 27 to 59 minutes (41 minutes average). See the Appendix for the complete survey instrument and semi-structured interview prompts.

Survey data were collected via Microsoft Forms and downloaded into an Excel spreadsheet for initial analysis. Additional analyses were completed using SPSS 26. Qualitative data from openended questions and interview transcripts were transcribed verbatim and analyzed using NVivo 10. Qualitative analysis began with initial coding looking for "repeated patterns of meaning" (Braun \& Clarke, 2006, p. 86). This step has as its goal the creation of "pithy labels for important features of the data" (Clarke \& Braun, 2013, p. 121) from the interview transcripts. In addition, 
constant comparison (Patton, 2015) was used to connect participant responses to the research questions to better understand "behavior, issues, and contexts with regard to [this] particular case" (Stake, 1995, p. 78). Following the initial rounds of coding, codes were arranged and rearranged into themes to highlight "coherent and meaningful pattern[s]" (Clarke and Braun, 2013 , p. 121) in the data. Through this process, three themes were identified.

\section{Findings}

Of the 29 students who completed the survey, 19 were enrolled in only classes that were modified; 7 had one unmodified and one modified class; 3 were in enrolled in only unmodified classes. Students reported having earned between 6 and 36 credits at CoastalU. For 7 students (24.1\%), spring 2020 was their first semester as a graduate student, and 3 students $(10.3 \%)$ reported that spring 2020 was their last semester.

\section{The Impact of the Pandemic on Work, School, and Home Life}

Participants were also asked about disruptions they experienced during the semester. Fourteen participants (48.3\%) indicated they had children engaged in learning at home "in a way that had an impact on your schedule." In addition, as outlined in Table 1, participants were asked how the emerging pandemic had affected their jobs. Participants were able to select as many of the employment outcomes as applied. Participants reported an average of $1.76(\mathrm{SD}=0.87)$ disruptive outcomes.

Table 1

Employment Outcomes Reported by Participants

Begin to work from home

$$
\text { Survey Prompt }(\mathrm{N}=29)
$$

Disruptions to the way you "normally" do your job (e.g., limitations $\underline{\text { Responses }}$

$\underline{\text { Percentage }}$

$24 \quad 82.8 \%$

to travel, changed work schedule, increased hours, etc.)

Significant reduction in hours or salary

21

$72.4 \%$

Complete loss of employment (for either yourself or a

$4 \quad 13.8 \%$

spouse/partner with whom you share expenses)

None of these apply to me

$2 \quad 6.9 \%$

The survey also provided a Likert-type scale to indicate the impact of pandemic-related restrictions such as "stay safe/stay home" orders or changes in shopping or eating on daily life. Students were given a 7-point scale ranging from $1=$ "I noticed very little difference" to $4=$ "It was somewhat disruptive, but manageable" to $7=$ "It felt disruptive in every way." In response to this question, no participants selected 1, 2, or 3. The mode was 4 and 7; the median was 5; the average was $5.48(\mathrm{SD}=1.30)$, suggesting that all participants found the pandemic at least "somewhat disruptive," while many found it significantly disruptive to life, work, and school. Intuitively, the number of negatives reported would be related to the reported "impact" of the pandemic. A Spearman correlation showed a low positive, but statistically significant correlation between these two variables $(\mathrm{rs}(29)=.387, \mathrm{p}<.05)$.

Responses to open-ended questions in this section of the survey highlighted the impact of schooling children at home, changes in housing situations, and limited time. Participants also described the challenge of balancing work and life. One participant noted "learning how to pull away from work" because working from home made it "easy to just keep working." Another stated: 
I had an overwhelming cloud of inertia. I have had clinical depression before, and it's not like that. I have had chronic fatigue syndrome, and it's not like that. My plants are dying, and it feels like a chore to take care of my dogs (who I love dearly). It's just really strange.

Based on these responses, the "novel" coronavirus, as it often called (SARS-CoV-2), also led to "novel" experiences for those seeking to navigate work, school, and life.

\section{The Response to Course Design Changes}

We were primarily interested in how students responded to the various course design changes. Survey questions asked which changes they took advantage of, which options they found most/least helpful, and how they would have managed course requirements without these options. Participants were instructed to select all that applied; Table 2 shows the extent to which student utilized the various options. On average, students reported utilizing 2.75 options $(\mathrm{SD}=$ 0.89). A Spearman correlation found no significant relationship between student self-reported "impact" of the pandemic and the number of course design changes students took advantage of $(\mathrm{rs}(29)=.232, \mathrm{p}=.232)$.

Table 2

Student Utilization of Course Design Changes

\section{Survey Prompt $(\mathrm{N}=29)$}

Removing deadlines for other assignments (i.e., turning in assignments after their originally posted due date)

Removing deadlines for discussion forums and responses

(i.e., working on discussion forums at a slower pace)

Opening all course content at the same time, to allow you to work at your own pace (i.e., working ahead of schedule)

Skipping a discussion forum or two (as made possible by the reduction in the total number of points in the class).

Exploring the option of swapping a given assignment with a work-related assignment.

None. I completed the course according to the originally posted schedule.

\begin{tabular}{|c|c|}
\hline Participants who & Percentage \\
\hline took this option & \\
\hline 24 & $82.8 \%$ \\
\hline 21 & $72.4 \%$ \\
\hline 18 & $62.1 \%$ \\
\hline 12 & $41.4 \%$ \\
\hline 2 & $6.9 \%$ \\
\hline 0 & $0.0 \%$ \\
\hline
\end{tabular}

To further explore participants' responses to the course design changes, we asked them which changes were most and least helpful (see Table 3). Of those enrolled in the unmodified course, 4 indicated that opening all the content at the same time would have been most helpful; 4 indicated that nothing would have been the most helpful; 1 indicated removing assignment deadlines and another indicated changing the discussion date deadlines would have been most helpful.

Table 3

Most and Least Helpful Course Design Changes

\begin{tabular}{|c|c|c|c|c|}
\hline \multirow{2}{*}{ Survey Prompt $(\mathrm{N}=28)$} & \multicolumn{2}{|c|}{ MOST helpful } & \multicolumn{2}{|c|}{ LEAST helpful } \\
\hline & Count & Percent & Count & Percent \\
\hline Removing deadlines for other as: & 16 & $55.2 \%$ & 0 & $0.0 \%$ \\
\hline
\end{tabular}


Opening all course content at the same time, to

allow you to work at your own pace

Skipping a discussion forum or two

Removing deadlines for discussion forums and

responses

Exploring the option of swapping a given

assignment with a work-related assignment.

No response or $\mathrm{n} / \mathrm{a}$

\begin{tabular}{rrrr}
7 & $24.1 \%$ & 1 & $3.4 \%$ \\
3 & $10.3 \%$ & 5 & $17.2 \%$ \\
2 & $6.9 \%$ & 1 & $3.4 \%$ \\
0 & $0.0 \%$ & 19 & $65.5 \%$ \\
& & 2 & $6.9 \%$ \\
\hline
\end{tabular}

We also asked participants to speculate on how they would have approached their coursework if no course design changes had been made (Table 4). Participants could check as many options as applied to their situation.

Table 4

Options Participants Would Have Explored if No Course Design Changes Had Been Made

\begin{tabular}{lrr} 
& Count & Percent \\
\cline { 2 - 3 } Tried to complete the course & 18 & $62.1 \%$ \\
Talked with the professor about changes in due dates and deadlines & 16 & $55.2 \%$ \\
Taken an incomplete in the course & 5 & $17.2 \%$ \\
Considered dropping the course & 4 & $13.8 \%$ \\
Probably dropped the course & 2 & $6.9 \%$ \\
\hline
\end{tabular}

In addition to the course modifications described here, CoastalU issued an institution-wide policy allowing students to "opt in" to Satisfactory/Unsatisfactory (S/U) grading, rather than receiving a traditional letter grade. Only one participant indicated taking advantage of this option. Among the reasons provided (in an open-ended prompt) for choosing traditional letter grading, several indicated concern for their overall GPA (if they took the S/U option) and a concern related to how a S/U grade would be perceived if they wished to pursue further doctoral studies. A few responses suggested that students did not understand the logistics of requesting $\mathrm{S} / \mathrm{U}$ grading. Many participants indicated that they did not feel it would be necessary, with some explicitly mentioning the assistance provided by the course modifications. As one participant noted, "Despite my appalling procrastination, [the professor] worked with us to ensure that we could be successful if we did the work. I felt that there would be no reason not to finish out the semester given every opportunity she offered us."

\section{The Experience of Mid-Course Design Changes}

In addition to surveying participants, three students agreed to be interviewed. These students were enrolled at least one class that modified its course design and one that did not. Qualitative data analysis on the interview transcripts led to the identification of three themes: managing the class, meeting learning objectives, and mitigating academic stress.

\section{Managing the Class}

Interview participants, like many other students, found themselves managing significant upheavals of work, personal, and academic matters. Two of the three participants work in student services within higher education; the third participant teaches sixth grade. Their work environments changed drastically in response to the pandemic, and each participant found they were also navigating personal challenges such as losing a second job or managing a child's autoimmune disease. 
In discussing the differences between the modified course and unmodified course, one participant described the differences between the two as "jarring." Another participant recalled that initially she wanted both classes to move to a set-your-own-deadlines model; however, by the end of the semester, she was grateful that one of the classes had maintained the original schedule, because it helped her stay on track. The third participant was in the last semester of her graduate program and found the differences between the two classes to be challenging to manage. In the end, she said of the modified class: "You have no idea how those changes impacted my whole educational outcome... I probably would have dropped out, stopped going to school."

\section{Meeting Learning Objectives}

Participants also talked about the process of learning and meeting learning objectives - even though so many things were changing and shifting in response to the pandemic. They discussed the challenging aspects of major assignments in each of the classes. One survey respondent indicated that they wanted the professor

To shorten the assignments or remove 1-2 papers. I believe having the assignments in place was not considerate of students' circumstances. It is awkward to have to request this from a professor and tell personal business that I am going through just to have the professor consider the option. I am a private person with much stress but should not have to share with a stranger.

Interview participants discussed the process of getting the work done and they highlighted aspects of particular assignments that were challenging. One participant recalled how "the finance class scared me" at the beginning of the semester, but she indicated that by the time the class was finished, she "learned so much" and had a "firm grasp" of the course concepts. For another interviewee, finishing the class was a point of pride: "When I start something, I finish what I start."

\section{Mitigating Academic Stress}

In discussing this particular semester and their experience as students, interview participants describe various sources of atypical stress. They found themselves caring for their own children and coworkers in new ways. As educators, they were managing significant shifts in their own work. One participant works in residence life, and he indicated that the response to the pandemic meant that

We've started adding a lot more sort of work, a lot of extra precautions, a lot of checking up on students, and just checking up on our RAs [resident assistants], seeing how they're doing. It just doesn't give me enough time to focus on my academics as I normally am used to.

Both interview participants and survey respondents highlighted the importance of flexibility for helping them navigate the semester. Based on the open-ended responses, it seems that one of the most helpful moves made was removing incremental deadlines and eliminating late penalties. This provided a "feeling of a safety net to ensure that I'm able to excel in the course" for one survey respondent.

It is interesting to note that interview participants highlighted the benefit of having modified and unmodified courses simultaneously. The modifications in one course provided a bit of a relief valve, as students could work, more or less, at their own pace through the semester. At the same time, having a schedule and timeline to follow in the other course provided structure and a bit of urgency that kept them on track for completing both classes. As one participant indicated, it was important to find a schedule to "keep the hours turning." 


\section{Discussion}

In many ways, research conducted in the immediate wake of COVID-19 is an exploration of an "extreme case" that creates a "once-in-a-lifetime opportunity to contribute" (Yin, as cited in Patton, 2015, p. 52) to the body of knowledge. Best practices and assumptions are tested in a new set of circumstances, allowing for a more comprehensive understanding. In this case, the mid-semester modifications to course design represented the instructors' best efforts to facilitate student persistence "in the moment." This follow-up study sought to understand the impact of those modifications.

\section{Helping Students Manage Disruptions}

While many of the news reports highlighted the impact of COVID-19 and related closures on students who suddenly found themselves shifting from in-person instruction to learning remotely (Baker, 2020; Johnson et al., 2020), this study demonstrates that students already studying online also experienced disruptions at work, school, and home. Of these participants, $82.8 \%$ were required to work from home, and $72.4 \%$ reported having to do their jobs differently. In addition, $20.6 \%$ experienced either a significant reduction in salary or a complete loss of employment, and many now found themselves responsible for shepherding children through remote learning. Morgan (2020) emphasized communicating with students throughout this crisis. Perhaps this is an element of social presence (Garrison et al., 2000) that is always important but that becomes critical in extreme situations. Helping students interact with each other as "real people" (p. 89) who are all managing coursework and chaos may be just as important as presenting content and grading assignments. While the mode of learning may not have changed for these fully online students, the pandemic was no less disruptive than for those who started the semester face-toface.

\section{Giving Students Options}

Weimer (2013) and others have suggested that students should be given greater control over selecting and designing course assignments. While this introduces an element of uncertainty that many instructors may find uncomfortable, for the students in this study, having greater control over the course schedule and assignment due dates proved helpful. Among these participants, $82.8 \%$ indicated taking advantage of relaxed deadlines for assignments, and $72.4 \%$ elected to work on "weekly" discussion forums at a slower pace; 55.2\% indicated that the removal of deadlines was the most helpful change made to the course design. In addition, students in the modified courses had the freedom to skip two or three discussion forums without affecting their final grade. And - although only one student took advantage of the option - students were given the freedom to suggest alternative assignments. Student response to these design changes runs counter to previous research that highlights the importance of helping students stay on schedule (Kesner, 2013; Wandler \& Imbriale, 2017). In addition, the instructor of the modified courses faced a lot more grading at the very end of the semester, rather than incrementally throughout the semester, which effectively reduced the feedback students received on their assignments. However, these changes gave students the freedom to integrate their coursework into work and family schedules that were in flux and the agency to manage the demands of the course in a way that worked best.

\section{Finding Balance}

Glenn (2018) found that when instructors infuse a "human touch" into their classes, students who face "life events" (p. 390) that have the potential to derail academic progress will be more likely to approach an instructor to seek assistance. Garrison et al.'s (2000) framework allows for this 
(social presence) while also maintaining a focus on the academic (cognitive presence) and instructional (teaching presence) mandate of a college course.

It can be challenging to find the right balance in this, especially during extreme events. Early in the pandemic, Mazak (2020) suggested an approach to teaching in crisis that fostered both "empathy for students and grace for yourself." Woven through participants' responses was a similar sense of managing competing demands and finding balance. When work or family demands required more effort, school took a back seat. When life settled into a bit of a routine, academics could be the focus. Those who were enrolled in both a modified and an unmodified course even described how the two different approaches complemented each other: Students could focus on the class that had due dates, but those due dates also served as a reminder that assignments for the modified course would eventually need attention. Giving students the agency to allocate their time individually enabled them to meet learning objectives and complete their classes successfully.

\section{Limitations and Future Research}

This is a small study, conducted with students in a single online program. Furthermore, the focus of the study - mid-semester course design changes - is narrow and the larger historical and social context in which the study was conducted is unique. As such, the findings presented here are not generalizable. Future research should explore the long-term impact of crisis responses to understand the effect of course concessions in one semester on student success in later semesters. This study also focused on graduate students; future studies should explore how undergraduate students respond to mid-semester course design changes and how they manage their own learning during extreme situations.

\section{Conclusion}

Non-traditional students have often been described as "one crisis away" from dropping out (e.g., Henry, 2020; Hensley, 2013). For many students, the COVID-19 pandemic created a cascade of crises. For the students in this study, where changes were made, students experienced those changes as a sort of release valve, allowing them to work out how to allocate their time to complete the course and manage the impact of the pandemic on their academic pursuits. That flexibility gave students the ability to control their own learning during a season when so much had spun out of control.

\section{Declarations}

The author declared no potential conflicts of interest with respect to the research, authorship, and/or publication of this article.

The author received approval from the ethics review board of the University of Houston-Victoria, USA for this study.

The author received no financial support for the research, authorship, and/or publication of this article. 


\section{References}

Abdelmatloub, R. (2020). Online learning during the COVID-19 pandemic and academic stress in university students. Revista Romaneasca pentru Educatie Multidimensionala, 12(1Sup2), 100-107. https://doi.org/10.18662/rrem/12.1sup2

Anderson, T., Rourke, L., Garrison, D. R., \& Archer, W. (2001). Assessing teaching presence in a computer conferencing context. Journal of Asynchronous Learning Networks, 5(2), 1-17.

Association of College and University Educators (ACUE). (2020). Establish a rhythm for participation. https://acue.org/wp-content/uploads/2020/03/Section-3_PG3_PredictableRhythm_CFIN.pdf

Al-Asfour, A. (2012). Online teaching: Navigating its advantages, disadvantages and best practices. Tribal College Journal of American Indian Higher Education, 23(3).

Baker, K. J. (2020). Panic-gogy: A conversation with Sean Michael Morris. The National Teaching \& Learning Forum, 28(4), 1-2. http://doi.org/10.1002/ntlf

Baker, R., Evans, B., \& Li, Q., \& Cung, B. (2019). Does inducing students to schedule lecture watching in online classes improve their academic performance? An experimental analysis of a time management intervention. Research in Higher Education, 60(4), 521-552.

https://doi.org/10.1007/s11162-018-9521-3

Barrett, D. (2019, January 31). How one professor learned to stop worrying and drop the deadline. The Chronicle of Higher Education.

https://www.chronicle.com/newsletter/teaching/2019-01-31

Barrett-Fox. R. (2020, March 12). Please do a bad job of putting your courses online. Any Good Thing. https://anygoodthing.com/2020/03/12/please-do-a-bad-job-of-putting-your-coursesonline/

Blumenstyk, G. (2020, March 15). Why coronavirus looks like a "Black Swan” moment for higher ed. Chronicle of Higher Education, 66(25).

Braun, V., \& Clarke, V. (2006). Using thematic analysis in psychology. Qualitative Research in Psychology, 3, 77-101.

Chen, L.-T., \& Liu, L. (2020). Social presence in multidimensional online discussion: The roles of group size and requirements for discussions. Computers in the Schools, 37(2), 116-140. https://doi.org/10.1080/07380569.2020.1756648

Davis, M. R., \& Ash, K. (2009). Swine-flu plans put e-learning in the spotlight. Education Week, 29(3), 1. 
Debattista, M. (2017). A comprehensive rubric for instructional design in e-learning. The International Journal of Information and Learning Technology, 35(2), 93-104. https://doi.org/10.1108/IJILT-09-2017-0092

Dushkevych, M., Barabashchuk, H., \& Hutsuliak, N. (2020). Peculiarities of student distance learning in emergency situation condition. Revista Romaneasca pentru Educatie Multidimensionala, 12(1Sup2), 71-77. https://doi.org/10.18662/rrem/12.1sup1/248

Elvers, G. C., Polzella, D. J., \& Graetz, K. (2003). Procrastination in online courses: Performance and attitudinal differences. Teaching of Psychology, 30(2), 159-162.

Fetzner, M. (2013). What do unsuccessful online students want us to know? Journal of Asynchronous Learning Networks, 17(1), 13-27. https://doi.org/10.24059/olj.v17i1.319

Garrison, D. R., Anderson, T., \& Archer, W. (2000). Critical inquiry in a text-based environment: Computer conferencing in higher education. The Internet and Higher Education, 2(2-3), 87-105. http://doi.org/10.1016/S1096-7516(00)00016-6

Glenn, C. W. (2018). Adding the human touch to asynchronous online learning. Journal of College Student Retention: Research, Theory \& Practice, 19(4), 381-393.

https://doi.org/10.1177/1521025116634104

Henry, L. (2020). Experiences of hunger and food insecurity in college. Palgrave Macmillan.

Hensley, K. P. (2013). Student retention in BSN programs [Doctoral dissertation, Old Dominion University]. ODU Digital Commons. https://digitalcommons.odu.edu/efl_etds/128 Holzweiss, P. C., Walker, D. W., Chisum, R., \& Sosebee, T. (2020). Crisis planning for online students: Lessons learned from a major disruption. Online Learning, 24(2), 22-37. https://doi.org/10.24059/olj.v24i2.2135

Jiang, M., Ballenger, J., \& Holt, W. (2019). Educational leadership doctoral students' perceptions of the effectiveness of instructional strategies and course design in a fully online graduate statistics course. Online Learning, 23(4), 296-312.

https://doi.org/10.24059/olj.v23i4.1568

Johnson, N., Veletsianos, G., \& Seaman, J. (2020). U.S. faculty and administrators' experiences and approaches in the early weeks of the COVID-19 pandemic. Online Learning Journal, 24(2), 6-21. https://doi.org/10.24059/olj.v24i2.2285

Kesner, R. M. (2013). Blending an asynchronous learning experience: A practiced approach to online course development. The Journal of the World Universities Forum, 6, 13-24.

Marshall, H. J. (2015). Faculty members' best practice standards in the design of higher education online courses [Doctoral dissertation, University of Toledo].

https://etd.ohiolink.edu/apexprod/rws_etd/send_file/send?accession=toledo1438618742\&disposi $\underline{\text { tion=inline }}$ 
Mazak, C. (Host). (2020, March 15). How to create a minimum viable semester in the midst of a global pandemic ("Bonus" episode) [Audio podcast episode]. In Academic Womxn Amplified. https://www.cathymazak.com/podcast/

Meyer, K. A., \& Wilson, J. L. (2011). The role of online learning in the emergency plans of flagship institutions. Online Journal of Distance Learning Administration, 4(1).

https://www.westga.edu/ distance/ojdla/spring141/meyer_wilson141.html

Michinov, N., Brunot, S., Le Bohec, O., Juhel, J., \& Delaval, M. (2010). Procrastination, participation, and performance in online learning environments. Computers \& Education, 56(2011), 243-252. https://doi.org/10.1016/j.compedu.2010.07.025

Morgan, H. (2020). Best practices for implementing remote learning during a pandemic. The Clearing House, 93(3), 135-141. https://doi.org/10.1080/00098655.2020.1751480

Murray, M., Pérez, J., Geist, D., \& Hedrick, A. (2012). Student interaction with online course content: Build it and they might come. Journal of Information Technology Education: Research, 11, 125-140. http://www.jite.informingscience.org/ documents/Vol11/JITEv11p125-140Murray1095.pdf

Parnia, A. (2020). As COVID-19 batters higher education, a proposal to move online fast. New England Journal of Higher Education. https://eric.ed.gov/?id=EJ1261473

Patton, M. Q. (2015). Qualitative research and evaluation methods: Integrating theory and practice (4th ed.). Sage.

Perotta, K., \& Bohan, C. H. (2020). A reflective study of online faculty teaching experiences in higher education. Journal of Effective Teaching in Higher Education, 3(1), 51-66.

Qayyum, A., Zipf, S., Gungor, R., \& Dillon, J. M. (2019). Financial aid and student persistence in online education in the United States. Distance Education, 40(1), 20-31.

https://doi.org/10.1080/01587919.2018.1553561

Stake, R. E. (1995). The art of case study research. Sage.

Stone, C., \& Springer, M. (2017). Interactivity, connectedness and 'teacher-presence': Engaging and retaining students online. Australian Journal of Adult Learning, 59(2), 146-169.

Sun, A., \& Chen, X. (2016). Online education and its effective practice: A research review. Journal of Information Technology Education: Research, 15, 157-190.

http://www.informingscience.org/Publications/3502

Terras, K., Mahar, P., Chiasson, K., Schroeder, S., \& Baker, M. (2017). Graduate student perceptions and experiences with connectivity in an asynchronous, online distance degree program. Journal of Higher Education Theory and Practice, 18(4), 60-73.

https://doi.org/10.33423/jhetp.v18i4.574 
Van, D., McLaws, M-L., Crimmins, J., MacIntyre, C. R., \& Seale, H. (2010). University life and pandemic influenza: Attitudes and intended behaviour of staff and students towards pandemic (H1N1) 2009. BMC Public Health, 10(130), 1-9. http://www.biomedcentral.com/14712458/10/130

Wandler, J. B., \& Imbriale, W. J. (2017). Promoting undergraduate student self-regulation in online learning environments. Online Learning, 21(2), 1-14.

http://doi.org/10.24059/olj.v21i2.881

Weimer, M. (2013). Learner-centered teaching: Five key changes to practice (2nd ed.). JosseyBass. 


\section{Appendix A \\ Research Instruments}

\section{Student Survey \\ <informed consent as the opening screen> Background Information}

1. Which graduate program are you enrolled in?
a. Adult and Higher Education
b. Master of Arts in Interdisciplinary Studies
c. Other

2. How many graduate credits have you earned at UHV (include credits you were enrolled in for Spring 2020)?

3. Please indicate which AHED classes you were enrolled in during Spring 2020. (select all that apply)

a. AHED 6331 - Program Planning in AHED

b. AHED 6346-Introduction to Student Services

c. AHED 6335-Diversity in Adult and Higher Education

d. AHED 6354-Higher Education Finance

4. Do any of these apply to you?

a. This is my first semester at UHV

b. This is my first semester as a graduate student at UHV

c. I took classes outside the AHED department in Spring 2020, such as English or Criminal Justice

d. This is my last semester at UHV

e. I took my AHED comprehensive exams in March 2020

f. None of these apply to me

\section{Impact of COVID-19 on your work and other circumstances}

5. As a result of COVID-19 quarantine, self-isolation, or other factors, did you experience any of the following employment outcomes, during the Spring 2020 semester (select all that apply):

a. Complete loss of employment (for either yourself or a spouse/partner with whom you share expenses)

b. Significant reduction in hours or salary

c. Disruptions to the way you "normally" do your job (e.g., limitations to travel, changed work schedule, increased hours, etc.)

d. Begin to work from home

e. None of these apply to me

6. As a result of COVID-19, did your children (including college-aged children) engage in learn-athome education/school in a way that had an impact on your schedule?
a. Yes
b. No
c. $\mathrm{n} / \mathrm{a}$

7. What impact did COVID-19 restrictions (e.g., "stay safe, stay home," changes in shopping/eating, etc.) have on your daily life (On a scale of 1-7: 1-I noticed very little difference; 4-it was somewhat disruptive, but manageable; 7 -it felt disruptive in every way)?

8. Do you have any additional comments on the impact COVID-19 had on your work or homelife?

Impact of COVID-19 on your academic pursuits

9. During Spring Break, Dr. Olson made significant changes to the course design in AHED 6335 (Diversity), AHED 6346 (Student Services), and AHED 6354 (Higher Ed Finance). Which of these changes did you take advantage of? (choose all that apply)

a. Removing deadlines for discussion forums and responses (i.e., you worked on discussion forums at a slower pace) 
b. Removing deadlines for other assignments (i.e., you turned in assignments after their originally posted due date?)

c. Opening all course content at the same time, to allow you to work at your own pace (i.e., you worked ahead of schedule)

d. Exploring the option of swapping a given assignment with a work-related assignment.

e. Skipping a discussion forum or two (as made possible by the reduction in the total number of points in the class).

f. None. I completed the course according to the originally posted schedule.

10. During Spring Break, Dr. Olson made significant changes to the course design in AHED 6335 (Diversity), AHED 6346 (Student Services), and AHED 6354 (Higher Ed Finance). Of these changes, which was the most helpful to you (choose only one)?

a. Removing deadlines for discussion forums and responses (i.e., you worked on discussion forums at a slower pace)

b. Removing deadlines for other assignments (i.e., you turned in assignments after their originally posted due date)

c. Opening all course content at the same time, to allow you to work at your own pace (i.e., you worked ahead of schedule)

d. Exploring the option of swapping a given assignment with a work-related assignment (i.e., you talked or e-mailed with Dr. Olson regarding an alternative assignment)

e. Skipping a discussion forum or two (as made possible by the reduction in the total number of points in the class).

11. During Spring Break, Dr. Olson made significant changes to the course design in AHED 6335 (Diversity), AHED 6346 (Student Services), and AHED 6354 (Higher Ed Finance). Of these changes, which was the least helpful to you (choose only one)?

a. Removing deadlines for discussion forums and responses (i.e., You worked on discussion forums at a slower pace)

b. Removing deadlines for other assignments (i.e., You turned in assignments after their originally posted due date)

c. Opening all course content at the same time, to allow you to work at your own pace (i.e., You worked ahead of schedule)

d. Exploring the option of swapping a given assignment with a work-related assignment (i.e., you talked or e-mailed with Dr. Olson regarding an alternative assignment)

e. Skipping a discussion forum or two (as made possible by the reduction in the total number of points in the class).

12. If you were a student in AHED 6331 (Program Planning), what one course design change would have been the most helpful to you (choose only one)?

a. Removing deadlines for discussion forums and responses (i.e., working on discussion forums at a slower pace)

b. Removing deadlines for other assignments (i.e., turning in assignments after their originally posted due date)

c. Opening all course content at the same time, to allow you to work at your own pace (i.e., working ahead of schedule)

d. Exploring the option of swapping a given assignment with a work-related assignment (i.e., talking with or e-mailing Dr. Kenahan regarding an alternative assignment)

e. Skipping a discussion forum or two (as made possible by the reduction in the total number of points in the class).

f. Nothing. The course design worked fine for me.

13. If no course changes had been offered (in 6335, 6346, 6354), do you think you would have (check all that apply)

a. Tried to complete the course.

b. Probably dropped the course 
c. Considered dropping the course

d. Taken an incomplete in the course

e. Talked with the professor about options for changes in due dates and deadlines

14. Did you take advantage of the satisfactory/unsatisfactory grading option?

a. Yes, for all of my classes.

b. Yes, for only one of my classes.

c. No, I chose to receive a (standard) letter grade.

Please share the reason for your decision

15. During Spring 2020 — specifically after spring break, when many restrictions and changes were implemented as a result of COVID-19 - what I needed most, academically, was:

16. Please share any other comments you have regarding your experience as a graduate student during Spring 2020 and course design changes that were made following the COVID-19 pandemic.

\section{Semi-structured Interview Prompts}

- Talk a bit about the impact of COVID-19 (and the related closures and public health requirements) on your academic experience this semester.

- If you could tell your pre-spring break self, one thing (i.e., before COVID-19 really took hold), what would you say?

We are primarily interested in exploring the impact of course design changes mid-semester. As a student who was enrolled in a class that did not make changes (AHED 6331) and at least one class that did make changes (AHED 6335, 6346, 6354), you are uniquely qualified to help us understand the student experience of these changes.

- What was the most positive aspect of your experience in 6331 (Program Planning)?

- What was the most challenging aspect of your experience in 6331 ?

- How were you feeling about AHED 6331 before spring break?

- What impact did COVID-19 have on the "community" in the classroom?

- Did you find it difficult to stay "on track" with discussion forums and assignments? Why or why not?

- Why do you think the instructor chose to maintain the original class schedule, due dates and deadlines?

- What was the most positive aspect of your experience in the other class $(6335,6346,6354)$ ?

- What was the most challenging aspect of your experience in this "other class"?

- How were you feeling about the "other class" $(6335,6346,6354)$ before spring break, before the course design changes?

- What impact did COVID-19 (and the course design changes) have on the "community" in the classroom?

- Did you find it difficult to stay "on track" with discussion forums and assignments? Why or why not?

- What was it like for you, juggling two classes - one with a more structured timeline and one that was more open?

- If you had to choose one approach or the other, which would you choose? Why?

- If we encountered a similar set of disruptive events again, what would you recommend in terms of course design? 